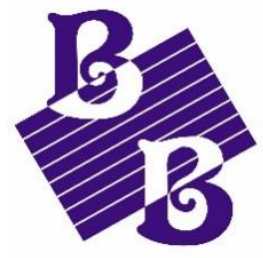

BioBacta
Journal of Bioscience and Applied Research

www.jbaar.org

\title{
Procalcitonin as a diagnostic marker for neonatal sepsis
}

\author{
Omar A. K. Al-azaowi ${ }^{1}$, Samir A. Abd El-kaream², Gihan Hosny ${ }^{1 *}$ \\ ${ }^{1}$ Environmental Health Division, Dept. of Environmental Studies, Institute of Graduate Studies \& Research, \\ Alexandria University, Egypt. \\ ${ }^{2}$ Dept. of Applied Medical Chemistry, Medical Research Institute, Alexandria University, Egypt. \\ * To whom correspondence should be addressed: Email: gihan1hosny @ gmail.com; \\ Tel: (+203) 4295007; Fax: (+203) 4285792.
}

DOI: 10.21608/jbaar.2018.152697

\begin{abstract}
Background: Sepsis is the most common cause of neonatal mortality. Isolation of bacteria from blood is the most specific and standard method used to diagnose neonatal sepsis. The drawback of culture-based diagnosis is the 24-48 hour assay time. Procalcitonin (PCT) has high specificity and positive predictive values. Thus, the current study was undertaken to investigate the released serum-procalcitonin as a biomarker for predicting neonatal sepsis among newly born infants. Subjects and Methods: A case-control study design was set to perform the underlying work. Forty-five neonates were included in this study. Blood samples were collected and processed for laboratory investigations and culture. Laboratory investigations included complete blood picture, blood culture and PCT. Results: Positive blood cultures were detected in all cases of the confirmed sepsis group (100\%) and $66.66 \%$ of cases of the suspected sepsis group. The ROC curve analysis, used to evaluate the diagnostic value of serum procalcitonin depending on the area under the curves (AUC), showed a very high AUC (91.7\%) corresponds to a better diagnostic test. The optimum cut off value of PCT $(<0.05$ $\mathrm{ng} / \mathrm{ml}$ ) was with a corresponding sensitivity of $100 \%$ and specificity of $83.33 \%$, a positive predictive value (100\%), and a negative predictive value (74.99\%). Conclusion: The current findings showed high sensitivity and specificity of the PCT test for diagnosis of neonatal sepsis. The results so far are very encouraging and may suggest that shortly the PCT may be used routinely for diagnosis of neonatal sepsis and can provide a lifesaving approach for newborns.
\end{abstract}

Keywords: Sepsis, biomarker, Procalcitonin (PCT), neonatal sepsis 


\section{Introduction}

Neonatal sepsis is a clinical syndrome characterized by systemic signs of infection and is accompanied by bacteremia in the first month of life. ${ }^{(1)}$ Sepsis is the most common cause of neonatal mortality and is responsible for $30-50 \%$ of total neonatal deaths, each year in developing countries. (2-4) The term neonatal sepsis refers to the systemic infection of neonates including septicemia, pneumonia, meningitis, arthritis, osteomyelitis, and urinary tract infection (Indian Council of Medical Research, 2003; Sankar et al., 2008) ${ }^{(4,5)}$.

National Neonatal Forum of India ${ }^{(4)}$ has defined neonatal sepsis as culture-negative or probable (clinical) sepsis when an infant having a clinical picture suggestive of septicemia and culturepositive sepsis when an infant has a clinical picture suggestive of septicemia, pneumonia or meningitis. Neonatal sepsis has been classified into early-onset (EOS) and late-onset (LOS) sepsis. EOS has onset $<72$ hours. LOS usually appears after $72 \mathrm{hr}$ of age. ${ }^{(6)}$ The manifestation of neonatal sepsis is vague and ill-defined. The Apgar score provides a convenient shorthand for reporting the status of neonate infant and the response to resuscitation. The Apgar score, the very first test given to a newborn, is performed in the delivery or birthing room right after the baby's birth. The test was designed to quickly evaluate a newborn's physical condition and to see if there's an immediate need for extra medical or emergency care. It refers to as an acronym for Appearance, Pulse, Grimace, Activity, and Respiration. The Apgar test is usually given to a baby twice: once at 1 minute after birth, and again at 5 minutes after birth. Sometimes, if there are concerns about the baby's condition or the score at 5 minutes is low, the test may be scored for a third time at 10 minutes after birth. ${ }^{(7)}$

Isolation of bacteria from blood is the most specific and standard method used to diagnose neonatal sepsis. The drawback of culture-based diagnosis is the $24-48$ hour assay time. Newer diagnostic tests are grouped into acute phase reactants; cell surface markers; granulocyte colonystimulating factor; cytokines; molecular genetics; and molecular cell proteomics. ${ }^{(8)}$ Acute phase reactants are groups of endogenous peptides produced by the liver as part of an immediate response to the infection or tissue injury. These reactants are; fibronectin, haptoglobin, lactoferrin, neopterin oromucosoid, C-reactive protein and procalcitonin. ${ }^{(9)}$

Procalcitonin (PCT) is produced by monocytes and hepatocytes. It begins to rise four hours after exposure to bacterial endotoxin, reaches its peak after six to eight hours, and remains raised for at least 24 hours, with a half-life of 25-30 hours. Procalcitonin $(2.3 \mathrm{ng} / \mathrm{ml})$ has high specificity and positive predictive values $(97 \%$ and $96 \%$, respectively), though with low sensitivity (48\%) for sepsis diagnosis. It was reported that procalcitonin $>2.3 \mathrm{ng} / \mathrm{ml}$ indicates a high likelihood for neonatal sepsis, and antibiotic therapy should be continued even in the presence of sterile cultures. However, it is not a readily available diagnostic assay in most institutions. ${ }^{(10)}$ The study aimed to monitor the released serum-procalcitonin as a biomarker for predicting neonatal sepsis among newly born infants examined at the hospital of Medical Research Institute, University of Alexandria, Egypt, delivered from June to December 2017.

\section{Subjects and Methods}


1. Subjects. Forty-five neonates were included in this study and were divided into three groups as follows: Group I: (suspected sepsis) involved 15 neonates with symptoms and signs suggestive of sepsis or at high risk of infection; Group II: (proven sepsis) included 15 neonates who are septic with a clinical picture of sepsis and laboratory data showing sepsis; and Group III: (Controls) included 15 healthy neonates with no evidence of sepsis. A convenient sample of neonates was taken from ElShatby hospital of maternity, Alexandria University, Egypt. Neonates in groups I and II were of matched age as the control group and informed consent was taken from parents of all contributors in this study.

Ethical considerations. This work was conducted according to the guidelines of the local Ethical Committee for sampling from a human. Oral consents were taken from parents to participate in the study.

Study sample exclusion criteria. Neonates with severe congenital anomalies, chromosomal abnormalities, intrauterine growth retardation, preterm, perinatal asphyxia and infant of a diabetic mother were excluded from the study.

\section{Methods}

Study design. A case-control study design was set to perform the underlying work.

Study setting. Three studied groups of neonates were involved in this study; Group I: suspected sepsis included 15 neonates; Group II: proven sepsis included 15 neonates; and Group III: healthy controls included 15 neonates. The study was set to collect blood samples from the target three groups previously described. Blood samples were then processed for laboratory investigations and culture. Venous blood was used for assaying $\mathrm{CBC}$, blood culture and procalcitonin. Laboratory investigations included: complete blood picture (CBC); blood cultures; and serum procalcitonin.

Data collection. To all neonates, the following data were collected: full history recording: (to detect risk factors for sepsis) including obstetric, prenatal, natal, postnatal and present history. Data were obtained from records of data sheets of neonates; and thorough clinical examination including general examination, cardiovascular examination, chest examination, neurological examination, abdominal examination and skin examination.

Blood Sampling. 2.5 millilitres of venous blood were withdrawn from suspected, proven sepsis neonates and healthy control group. For venous blood: The first part $(1.5 \mathrm{ml})$ was pipetted into a tube containing EDTA to be used for assaying CBC and blood culture. The second part $(1 \mathrm{ml})$ was allowed to clot thoroughly for 30 minutes then centrifuged at 1000xg for 15 minutes for separating serum. Serum was used for assaying procalcitonin.

\section{Laboratory Investigations}

Complete Blood Picture (CBC). For the determination of $\mathrm{CBC}, 0.5$ millilitres of venous blood was collected in vacutainers containing ethylenediaminetetra-acetic acid (EDTA) and analyzed by auto hematology analyzer Mindray BC-3000 plus (Mindray Bio-Medical Electronics Co., Ltd, United States of America). Calibration of the machine was done every morning before processing. The normal ranges were; 5000 and 30,000/ml for WBC, 4700 and 9400 for neutrophils, 5000 and $5000 / \mathrm{ml}$ for lymphocytes and 150,000 and 
$450,000 / \mathrm{ml}$ for platelets. The extreme value on either side was suggestive of ongoing neonatal sepsis.

Blood Culture. Blood culture aseptic techniques were performed as follow; approximately one milliliter of blood was inoculated into the pediatric blood culture bottles (ready to use Hexa-Biotec blood culture Co., Ltd, Egypt). Blood culture bottles were incubated at $37^{\circ} \mathrm{C}$ for 24 hours after which the aliquots were sub-cultured on solid agar plates; MacConkey, blood and chocolate agars (OXOID Ltd, Basingstoke, Hampshire, England) for up to 96 hours before being regarded as no growth.

Serum Procalcitonin. Serum procalcitonin, PCT, was detected semi-quantitatively by a rapid immunochromatographic technique using a commercially available test kit (PCT-Q, BRAHMS Diagnostica GmbH, Berlin, Germany) in 30 minutes. 200 microliters of serum were applied onto the test strip. PCT in the sample is bound by mouse anti-calcitonin antibodies conjugated with colloidal gold to form a complex. This complex moves using capillarity through an area containing fixed anticalcitonin antibodies to form a sandwich complex that can be seen as a reddish band. The color intensity of the band was directly proportional to the PCT concentration of the sample. Normal serum and plasma levels of PCT are less than $0.5 \mathrm{ng} / \mathrm{ml}$. Levels above this value were considered as pathological. The result was read and interpreted as per the manufacturer's recommendations: PCT > $10 \mathrm{ng} / \mathrm{ml}$, severe bacterial sepsis or septic shock; PCT 2 to $10 \mathrm{ng} / \mathrm{ml}$, severe systemic inflammatory response, most likely due to sepsis unless other causes are known; PCT 0.5 to $2 \mathrm{ng} / \mathrm{ml}$, a systemic infection cannot be excluded; and PCT $<0.5 \mathrm{ng} / \mathrm{ml}$, local bacterial infection possible; sepsis unlikely.
Statistical Analysis of the Data. Data were fed to the computer and analyzed using IBM SPSS software package version 20.0. Quantitative data were described using mean and standard deviation. For normally distributed data, a comparison between two independent populations was done using an independent t-test while more than two populations were analyzed using F-test (ANOVA) to be used and Post Hoc test (LSD). The significance of the obtained results was judged at the $5 \%$ level.

\section{Results}

Results revealed that sepsis was more in neonates aged $>3$ days age (late-onset sepsis) than newborns of $<3$ days age (early-onset sepsis), as indicated by ANOVA ( $\mathrm{F}=32.696, \mathrm{p}=.001)$. Incidence of sepsis was more seen in preterm with a gestational age of $<37$ weeks in comparison to term newborns. This difference was statistically insignificant, using ANOVA ( $\mathrm{F}=0.253, \mathrm{p}=0.778)$. Incidence of sepsis was more in newborns delivered by caesarean section than normal delivery. This difference was statistically insignificant using ANOVA $(\mathrm{F}=0.262, \mathrm{p}=0.770)$. Incidence of sepsis was more among low birth weight newborns than normal birth weight newborn. This difference was statistically insignificant using ANOVA $(\mathrm{F}=0.653$, $\mathrm{p}=0.526$ ). The incidence of sepsis was more in male than female newborns. This difference was statistically insignificant using ANOVA ( $\mathrm{F}=0.263$, $\mathrm{p}=0.770$ ).

Table 1 shows the APGAR score distribution among study subjects. The Apgar score provides a convenient shorthand for reporting the status of the newborn infant and the response to resuscitation. It refers to as an acronym for Appearance, Pulse, 
Grimace, Activity, and Respiration. The Apgar test is usually given to a baby twice: once at 1 minute after birth, and again at 5 minutes after birth.

APGAR (1 min) and APGAR (5 min) were in the lowest values among group II neonates followed by a group I neonates while the highest APGAR score was among group III neonates (control). These differences were statistically significant using ANOVA ( $\mathrm{F}=48.731, \mathrm{p}=0.002$ and $\mathrm{F}=25.345$, $\mathrm{p}=0.007$, respectively). Clinical sepsis score was higher among group II newborns more than group I newborns. This difference was statistically significant using a t-test $(\mathrm{T}=4.146, \mathrm{p}=0.016)$

Table 1. APGAR score distribution among study subjects.

\begin{tabular}{|c|c|c|c|c|c|}
\hline & \multicolumn{3}{|c|}{ Studied Groups } & \multirow[b]{2}{*}{$\mathbf{F}$} & \multirow[b]{2}{*}{ P-value } \\
\hline & $\begin{array}{l}\text { Group I } \\
\mathbf{N}=15\end{array}$ & $\begin{array}{c}\text { Group II } \\
\qquad \mathbf{N}=15\end{array}$ & $\begin{array}{c}\text { Group III } \\
\qquad \mathbf{N}=15\end{array}$ & & \\
\hline APGAR $($ Mean \pm SD $)$ & & & & & \\
\hline$(1 \mathrm{~min})$ & $6.5 \pm 0.13$ & $5.7 \pm 0.15$ & $8.5 \pm 0.17$ & 48.731 & 0.002 \\
\hline$(5 \mathrm{~min})$ & $8.5 \pm 0.18$ & $7.8 \pm 0.16$ & $9.9 \pm 0.19$ & 25.345 & 0.007 \\
\hline
\end{tabular}

Table 2 shows organisms revealed from blood cultures and antibiotic sensitivity. Klebseilla and Staph ssp. showed the highest percentages being $(20 \%)$ in blood cultures of Group I followed by E. coli (13.3\%), and lastly Pseudomonas and Enterobacter (6.6\%). In Group II, Klebseilla showed the highest percentage being (33.3\%) followed by Staph spp. (26.6\%) followed by E.coli (20\%) followed by Pseudomonas (13.3\%), and lastly Enterobacter (6.6\%). The organisms in Group I was sensitive to Meropenem (40\%) followed by Amikacin, Ciftazidim (13.3\%), and then Ceftriaxon, Ciprofloxacin, Cefepim, Gentamycin, Vancomycin (6.6\%). Also, the organisms in Group II were sensitive to Meropenem (33.3\%) followed by Amikacin (20\%) then Vancomycin (13.3\%) and Ciprofloxacin, Ceftriaxon, Gentamycin, Ciftazidim (6.6\%).

Table 2. Organisms in blood cultures and antibiotic sensitivity.

\begin{tabular}{|c|c|c|c|c|}
\hline & \multicolumn{2}{|c|}{ Studied Groups } & \multirow[b]{2}{*}{$\mathbf{T}$} & \multirow[b]{2}{*}{ P-value } \\
\hline & $\begin{array}{c}\text { Group I } \\
\mathrm{N}=15\end{array}$ & $\begin{array}{c}\text { Group II } \\
\mathbf{N}=15\end{array}$ & & \\
\hline No growth & $5(33.33 \%)$ & $0(0.00 \%)$ & \multirow{2}{*}{49.0} & \multirow{2}{*}{0.001} \\
\hline Growth (Organisms) & $10(66.66 \%)$ & $15(100 \%)$ & & \\
\hline Gram positive & $3(20.00 \%)$ & $4(26.66 \%)$ & \multirow{2}{*}{33.28} & \multirow{2}{*}{0.001} \\
\hline Gram negative & $7(46.66 \%)$ & $11(73.33 \%)$ & & \\
\hline Klebseilla. spp & $3(20.00 \%)$ & $5(33.33 \%)$ & & \\
\hline Staph. spp & $3(20.00 \%)$ & $4(26.66 \%)$ & & \\
\hline Escherichia coli & $2(13.33 \%)$ & $3(20.00 \%)$ & & \\
\hline Pseudomonas & $1(6.66 \%)$ & $2(13.33 \%)$ & & \\
\hline Enterobacter & $1(6.66 \%)$ & $1(6.66 \%)$ & & \\
\hline
\end{tabular}


Table 3 shows the serum PCT level among study subjects. Levels of PCT were above normal in most of the newborns with suspected and proven sepsis (Group I \& II) compared to healthy control. The differences were statistically significant using ANOVA at $\mathrm{p}=0.001$.

Table 3. Serum PCT levels among the study subjects.

\begin{tabular}{||l|c|c|c|c|c||}
\hline & \multicolumn{3}{|c|}{ Studied Groups } & \multirow{3}{*}{ F } & \multirow{2}{*}{ P-value } \\
\cline { 2 - 4 } & $\begin{array}{c}\text { Group I } \\
\text { N= 15 }\end{array}$ & $\begin{array}{c}\text { Group II } \\
\text { N = 15 }\end{array}$ & $\begin{array}{c}\text { Group III } \\
\text { N = 15 }\end{array}$ & & \\
\hline Serum PCT $(\mathrm{ng} / \mathrm{ml})$ & & & & & \\
$<0.5 \mathrm{ng} / \mathrm{ml}$ & $0(0.00 \%)$ & $0(0.00 \%)$ & $15(100 \%)$ & & \\
$\geq 0.5 \mathrm{ng} / \mathrm{ml}$ & $7(46.66 \%)$ & $0(0.00 \%)$ & $0(0.00 \%)$ & 164.745 & 0.001 \\
$\geq 2 \mathrm{ng} / \mathrm{ml}$ & $8(53.33 \%)$ & $6(40.00 \%)$ & $0(0.00 \%)$ & & \\
$\geq 10 \mathrm{ng} / \mathrm{ml}$ & $0(0.00 \%)$ & $9(60.00 \%)$ & $0(0.00 \%)$ & & \\
\hline
\end{tabular}

Table 4 and Figure 1 show agreement (sensitivity, specificity and accuracy for PCT. The ROC curve analysis was used to compare the diagnostic values of PCT and culture result depending on the area under the curves (AUC). The higher AUC corresponds to a better diagnostic test. PCT showed significant AUC (91.7\%, $\mathrm{p}<0.001)$ with a sensitivity of $83.337 \%$ and specificity of $100 \%$.

Table 4. Sensitivity, specificity and accuracy for PCT.

\begin{tabular}{|c|c|c|c|c|c|c|c|}
\hline & $\frac{2}{4}$ & 2 & 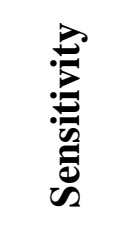 & 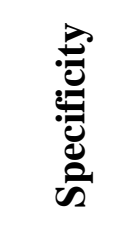 & $\overrightarrow{2}$ & 文 & 。 \\
\hline Serum PCT & 0.917 & $<.0001$ & 83.33 & 100.0 & 100.0 & 74.99 & $0.795-0.978$ \\
\hline
\end{tabular}




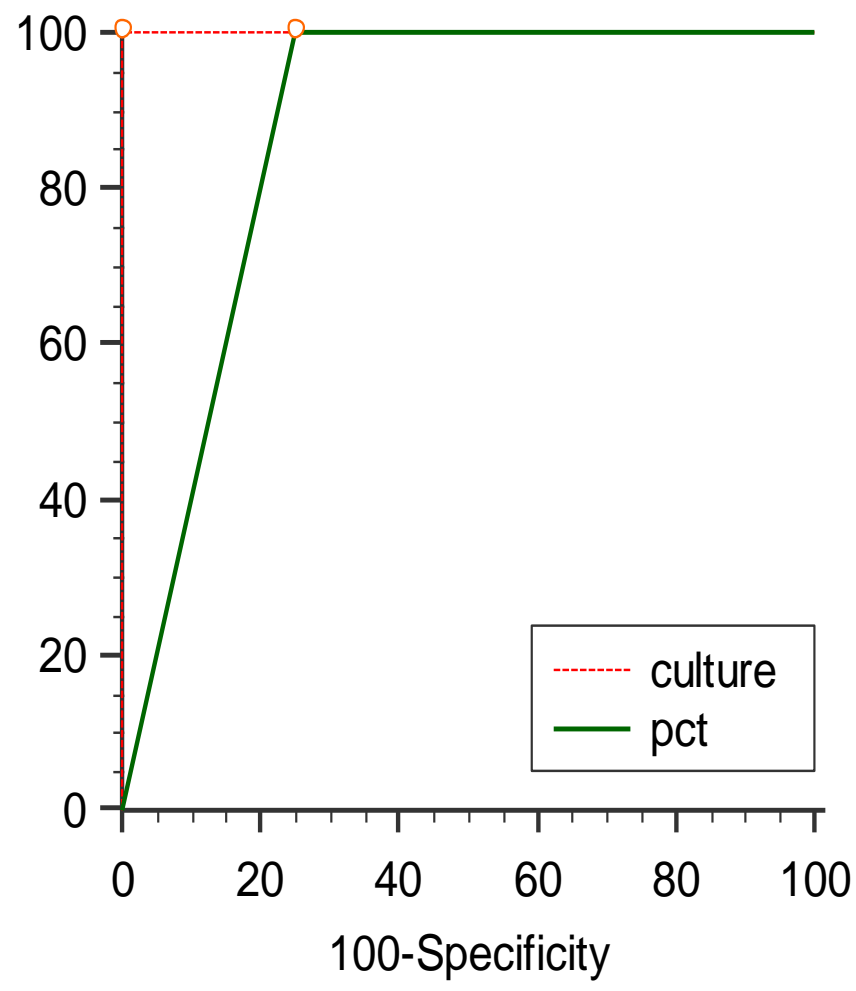

Figure 1. ROC curve for PCT. 


\section{Discussion}

In the present study, late-onset septicemia (LOS) was more common than early-onset septicemia (EOS). This is probably because EOS reflects transplacental or, more frequently, ascending infections from the maternal genital tract, whereas LOS is associated with the postnatal nosocomial or community environment, with the peak incidence reported to be between the $10^{\text {th }}$ and $22^{\text {nd }}$ day of life. $^{(11-15)}$ Since the early 1980 s, epidemiological studies have observed a general reduction in EOS, probably due to advances in obstetric care and the use of prophylactic intrapartum antibiotics to prevent infections caused by Group B Streptococcus. Meanwhile, the incidence of LOS has increased in parallel with the improved survival of premature infants, especially in those with very low birth weight, indicating the role of hospitalization and life-sustaining medical devices in the pathogenesis of neonatal LOS. ${ }^{(16,17)}$

Results revealed that sepsis was more common in preterm neonates with gestational age $<37$ weeks than in term newborns with gestational age $\geq 37$. This is probably due to complications of labor and delivery and the immaturity of innate and adaptive immunity. ${ }^{(18,19)}$ Also, one of the important risk factors was a premature rupture of the membrane (PROM) which was more prevalent in $30 \%$ of cases. The fact lying here is that PROM poses a risk of ascending infection to the fetus. ${ }^{(19,20)}$

Sepsis was shown to be more common in caesarean section $(63 \%)$ than normal delivery in (37\%). This is probably due to an increased number of high-risk pregnancies admitted in this hospital resulting in increased caesarean section. ${ }^{(20)}$ Also, it was shown that infection was more common in the low birth weight baby compared to babies of normal birth weight in agreement with results reported in other studies. ${ }^{(19,20)}$

In this study, sepsis was more common in males (60\%) than females (40\%), which is consistent with the findings of Berger et $a l .^{(21)}$ This might be attributed to the attitude of parents to seek medical services more often for their male babies rather for female babies in this region.

It was also found that there were statistically significant differences among the study groups regarding APGAR (1 min) and APGAR (5 min) at a p-value equal to 0.007 . This agrees with the study of Yousef et al. ${ }^{(22)}$ who observed that, a 5-minute Apgar score $<7$ carries a significantly higher risk of sepsis than infants with higher scores and that Apgar scores less than 5 at one minute may be due to sepsis, especially with the presence of risk factors for infection. Furthermore, low Apgar scores usually necessitate more prolonged and aggressive resuscitation which is a known risk factor for sepsis. ${ }^{(23)}$

In the current study, it was found that positive blood cultures were found in all of the confirmed sepsis group (100\%) and $66.67 \%$ of the suspected sepsis group. Klebseilla and Staph ssp. showed the highest percentages (20\%) in blood cultures of Group I followed by E. coli (13.3\%), and lastly Pseudomonas and Enterobacter (6.6\%). In Group II, Klebseilla showed the highest per cent of incidence (33.3\%) followed sequentially by Staph spp. (26.6\%), E.coli (20\%), Pseudomonas (13.3\%), and lastly Enterobacter (6.6\%). These findings are in agreement with Abdel-Hady and Zaki (2003) $)^{(24)}$ who reported that klebsilla was found in $41.3 \%$ of patients. Also, Badrawi et al. $(2005)^{(25)}$ reported that klebsiella was found in $63.6 \%$. Boseila et al. (2011) ${ }^{(26)}$ found that Klebseilla dominated the 
organisms isolated from the blood culture $(35 \%)$,

followed by Pseudomonas (20\%), Coagulase Negative Staphylococci (10\%), Group B Streptococci (10\%), Staph. Aureus (10\%) and Enterobacter (15\%). These results were consistent with Aletayeb et al. (2011) ${ }^{(27)}$ and Shah et al. (2012) (28) who reported that the percentage of Gramnegative isolates from sepsis cases were $92.8 \%$ and $52 \%$, respectively. On the other hand, Kaseb et al. $(2004)^{(29)}$ found that gram-positive bacteria as staphylococcus were isolated in $50 \%$ of the cases, while Klebsiella was found in $26.7 \%$. Also, Marchant et al. (2013) ${ }^{(30)}$ found that gram-positive organisms accounted for the majority of neonatal sepsis cases (up to $70 \%$ ) while sepsis due to gramnegative organisms accounted for (15 to 20\%). Ballot et al. (2012)(31) found that gram-positive infections predominated in EOS, with Streptococcus Agalactiae being the most common pathogen. Muhammad et al. (2010) ${ }^{(32)}$ found that Klebisella and Moraxella were the most common isolates of LOS. On the contrary, Li et al. (2013) $)^{(33)}$ also reported that coagulase-negative Staphylococcus (CoNS) was the major grampositive bacteria in LOS (54.4\%).

This variability in the etiology between EOS and LOS can be explained by the fact that EOS is conventionally regarded as maternally-acquired, with causative organisms, such as gram-negative organisms which are usually found in the maternal genital tract, whereas LOS is considered environmental in origin, either hospital or community-acquired. ${ }^{(34)}$ Intervention procedures may affect the distribution of microorganisms. As regard EOS, after the introduction of intrapartum GBS prophylaxis, the rate of this infection increases and allows gram-negative predominance to occur. While the predominance of gram-positive organisms in LOS is attributed to the poor infection control attitude in hospitals especially in developing countries. ${ }^{(35)}$

Procalcitonin (PCT) has been proposed as a marker of bacterial sepsis in critically ill patients. PCT is a precursor of calcitonin and is a 116 amino acids protein. ${ }^{(34,36)}$ In contrast to calcitonin that has a short half-life of $10 \mathrm{~min}$, PCT has a much longer half-life of 25-30 hr. In healthy persons, PCT levels are barely detectable. ${ }^{(36)}$ Although the exact sites of production of PCT in sepsis have not been identified, monocytes and hepatic cells are believed to be potential sources. ${ }^{(34,37)}$ Bacterial lipopolysaccharide (LPS) is a potent inducer of PCT release into the systemic circulation. ${ }^{(38)}$ PCT concentration starts to rise from 3-4 hrs after an endotoxin challenge with a peak after about 6 hrs, and remain increased for over $24 \mathrm{hr} .{ }^{(34,39)}$ Many authors found that PCT is a promising marker for the diagnosis of neonatal sepsis. ${ }^{(34-40)}$ In these studies, PCT sensitivity in the early diagnosis of neonatal sepsis was found to be $83-100 \%$ while the specificity was $70-100 \% .^{(36-40)}$ But some investigators questioned the diagnostic accuracy of PCT in detecting neonatal sepsis. In these studies, it was reported that serum levels had also increased in non-infected neonates with perinatal asphyxia, intracranial hemorrhage, pneumothorax, or after resuscitation, and these conditions had negatively affected the specificity of PCT. ${ }^{(40,41)}$

In the present study, PCT showed a sensitivity of $83.33 \%$, specificity of $100 \%$, and positive predictive value of $100 \%$ and negative predictive value of $74.99 \%$. To evaluate the PCT test performance, ROC curve using sensitivity and specificity of PCT was made for cut off value of $<0.05 \mathrm{ng} / \mathrm{ml}$. Area under the curve was found to be 
equal (0.917). These findings are in agreement with

other studies that reported that the PCT test appeared to be useful for the diagnosis of neonatal sepsis. ${ }^{(34-46)}$

The current findings showed high sensitivity and specificity of the PCT test for diagnosis of neonatal sepsis. The results so far are very encouraging and may suggest that shortly the PCT may be used routinely for diagnosis of neonatal sepsis and can provide a life-saving approach for newborns.

\section{References}

1. Upadhyay A, Aggarwal R, Kapil A, Singh S, Paul VK, Deorari AK. Profile of neonatal sepsis in a tertiary care neonatal unit from India: A retrospective study. Journal of Neonatology 2006; 20: 50-57.

2. Deorari Ashok K. For the Investigators of the National Neonatal Perinatal Database (NNPD). Changing pattern of bacteriologic profile in Neonatal Sepsis among intramural babies. Journal of Neonatology 2006; 20: 815.

3. Zaidi AK, Huskins WC, Thaver D, Bhutta ZA, Abbas Z, Goldmann DA. Hospitalacquired neonatal infections in developing countries. Lancet 2005; 365: 1175-88.

4. Indian Council of Medical Research New Delhi. National Neonatal Perinatal Database. Report 2002-2003. http://www.newbornwhocc.org/pdf/nnpd_repo rt_2002-03.

5. Sankar MJ, Agarwal A, Deorari AK, Paul VK. Sepsis in the newborn. Indian J Pediatr 2008; 75: 261-6.

6. Say L, Chou D, Gemmill A, Tunçalp Ö, Moller AB, Daniels J et al. Global causes of maternal death: a WHO systematic analysis. Lancet Glob Health. 2014; 2(6): e323-33. DOI: $10.1016 / \mathrm{S} 2214-109 \mathrm{X}(14) 70227-\mathrm{X}$.

7. Aggarwal R, Sarkar N, Deorari AK, Paul VK. Sepsis in the newborn. Indian J Pediatr 2001; 68: 1143-7.
8. Kale A, Jaybhaye D, Bonde V. Neonatal sepsis: An update. Ind J Neonat. 2014; 4(4): 39-51.

9. Richard A, Polin L, Elvira P. Bacterial sepsis and meningitis. William $\mathrm{T}$, Roberta A, Christine A. Disease of the Newborn, $8^{\text {th }}$ ed., 2005; pp. 551-77.

10. Turner D, Hammerman C, Rudensky B, Schlesinger Y, Schimmel MS. The role of procalcitonin as a predictor of nosocomial sepsis in preterm infants. Acta Paediatr 2006; 95:1571-6.

11. Chan T. and Gu F. Early diagnosis of sepsis using serum biomarkers. Expert Rev Mol Diagn. 2011; 11: 487-96.

12. Boghossian NS, Page GP, Bell EF, Stoll BJ, Murray JC, Cotten CM, et al. Late-onset sepsis in very low birth weight infants from singleton and multiple-gestation births. J Pediatr 2013; 162: 1120-4.

13. Vergnano S, Menson E, Kennea N, Embleton $\mathrm{N}$, Russell $\mathrm{AB}$, Watts $\mathrm{T}$, et al. Neonatal infections in England: the Neon in surveillance network. Arch Dis Child Fetal Neonatal Ed 2011; 96: 9-14.

14. Tsai MH, Hsu JF, Chu SM, Lien R, Huang $\mathrm{HR}$, Chiang MC, et al. Incidence, clinical characteristics, and risk factors for adverse outcome in neonates with late onset sepsis. Pediatr Infect Dis J 2014; 33: 7-13.

15. Hammoud MS, Al-Taiar A, Thalib L, AlSweih N, Pathan S, Isaacs D. Incidence, aetiology and resistance of late-onset neonatal sepsis: a five-year prospective study. J Paediatr Child Health 2012; 48: 6049.

16. Bizzarro MJ, Raskind C, Baltimore RS, Gallagher PG. Seventy-five years of neonatal sepsis at Yale: 1928-2003. Pediatrics 2005; 116: 595-602.

17. Shim GH, Kim SD, Kim HS, Kim ES, Lee HJ, Lee JA, et al. Trends in epidemiology of neonatal sepsis in a tertiary center in Korea: a 26-year longitudinal analysis, 1980-2005. J Korean Med Sci 2011; 26: 284-9.

18. Wynn JL, Levy O. Role of innate host defenses in susceptibility to early-onset neonatal sepsis. Clin Perinatol 2010; 37: 307-37. 
19. Naher BS, Mannan MA, Noor K, Shahiddullah M. Role of serum procalcitonin and C-Reactive Protein in the diagnosis of neonatal sepsis. Bangladesh Med Res Counc Bull 2011; 37: 40-46.

20. Romero R, Quintero R, Oyarzun E, Wu YK, Sabo V, Mazor $M$, et al. Intra-amniotic infection and the onset of labor in preterm premature rupture of the membranes. Am $\mathbf{J}$ Obstet Gynecol. 1988; 159: 661-6.

21. Berger A, Salzer HR, Weninger M, Sageder B, Aspock C. Septicemia in an Austrian neonatal intensive care unit, a 7-year analysis. Act a Paediatr 1998; 87: 1066-9.

22. Yousef ARA, Ismail IS, Imam SS, Shaheen $\mathrm{KY}$. Interleukin- 1 and phospholipase $\mathrm{A} 2$ in septic newborns. Thesis submitted for partial fulfillment of master degree in pediatrics, faculty of medicine, Ain-Shams University; 2003.

23. Gomella TL, Cunningham MD, Eyal FG, Zenk EK. Tricia Lacy Gomella clinical manual of neonatology $\left(5^{\text {th }} \mathrm{ed}\right)$. McGraw-Hill Co; 2004.

24. Abdel-Hady HE and Zaki ME: Evaluation of soluble E-selectin as a marker for neonatal sepsis. Egyptian J neonatol 2003; 4: 69-78.

25. Badrawi NH, Bashir MM, Iskander IF and Saied DA. Neonatal infections in NICU: magnitude of the problem. Kasr El-Aini Med J 2005; 11: 181-95.

26. Boseila S, Seoud I, Samy G, El-Gamal H, Ibrahim TS, Ahmed A, et al. Serum neopterin level in early onset neonatal sepsis. J Amer Sci 2011; 7: 343-52.

27. Aletayeb M, Khosravi A, Dehdashtian M. Identification of bacterial agents and antimicrobial susceptibility of neonatal sepsis: A 54-month study in a tertiary hospital. African J Microbiol Res 2011; 5: 528-31.

28. Shah A, Mulla S, Revdiwala S. Neonatal sepsis: High antibiotic resistance of bacterial pathogens in a Neonatal Intensive Care Unit in a Tertiary care hospital. J Clin Neonatol 2012; 1: 72-5.

29. Kaseb A, Abou El-Ela M, Abou Hussein H. The value of procalcitonin in the diagnosis of neonatal sepsis. M.Sc. thesis (Pediatrics), Faculty of Medicine, Cairo University; 2004.
30. Marchant E, Boyce G, Sadarangani M, Lavoie PM. Review article Neonatal Sepsis due to Coagulase-Negative Staphylococci. Clin Develop Immunol 2013; 2013: 1-10. Article ID 586076, 10 pages. doi:10.1155/2013/586076.

31. Ballot D, Nana T, Sriruttan C, Cooper PA. Bacterial bloodstream infections in neonates in a developing country. ISRN Pediatr 2012; 2012: 1-10. Article ID 508512, 10 pages. DOI: $10.5402 / 2012 / 508512$.

32. Muhammad Z, Ahmed A, Hayat U, Wazir MS, Rafiyatullah, Waqas H. Neonatal sepsis: caustive bacteria and their resistance to antibiotics. J Ayub Med Coll Abbottabad 2010; 22: 33-6.

33. Li Z, Xiao Z, Li Z, Zhong Q, Zhang Y, Xu F. 116 cases of neonatal early-onset or lateonset sepsis: A single center retrospective analysis on pathogenic bacteria species distribution and antimicrobial susceptibility. Int J Clin Exp Med 2013; 6: 693-9.

34. Das D, Barua N, Sharma JN. Evaluation of blood culture and serum procalcitonin for diagnosis of septicaemia in paediatric patients. Indian J Microbiol Res 2016; 3: 250-4.

35. Weinschenk NP, Farina A, Bianchi DW. Premature infants respond to early-onset and late onset sepsis with leukocyte activation. $\mathbf{J}$ Pediatr 2000; 137: 345-50.

36. Athhan F, Akagunduz B, Genel F, Bak M, Can D. Procalcitonin: A marker of neonatal sepsis. J Trop Pediatr 2002; 48: 10-4.

37. Carrol ED, Thomson AP, Hart CA. Procalcitonin as a marker of sepsis. Int $\mathbf{J}$ Antimicrobe Agents 2002; 20: 1-9.

38. Carrol ED, Newland P, Riordan FAI, Thomson APJ, Curtis N, Hart CA. Procalcitonin as a diagnostic marker of meningococcal disease in children presenting with fever and a rash. Arch Dis Child 2002; 86: 282-5.

39. Gendrel D, Raymond J, Coste J. Comparion of procalcitonin with C-reactive protein, interleukin-6 and interferon-alpha for differentiation of bacterial vs. viral infections. Pediatr Infect Dis 1999; 18: 87581.

40. Vincent JL. Procalcitonin: The marker of sepsis? Crit Care Med 2000; 28:1226-8. 
41. Monneret G, Labaune JM, Isaac C, Bienvenu F, Putet G, Bienvenu J. Procalcitonin and Creactive protein levels in neonatal infections. Acta Paediatr 1997; 86: 209-12.

42. Janota J, Stranak Z, Belohlavkova S, Mudra K, Simak J. Postnatal increase of procalcitonin in premature newborns is enhanced by chorioamnionitis and neonatal sepsis. Eur J Clin Invest 2001; 31: 978-83.

43. Bonac B, Derganc M, Wraber B, Wraber B, Hojiker S. Interleukin-8 and procalcitonin in early diagnosis of early severe bacterial infection in critically ill neonates. Pflugers Arch-Eur J physiol 2000; 440: 72-4.

44. Enguix A, Rey C, Concha A, Medina A, Coto D, Dieguez MA. Comparison of procalcitonin in neonate and children. Intensive care Med 2001; 27: 211-5.

45. Blommendahl J, Janas M, Laine S, Miettinen A, Ashorn P. Comparison of procalcitonin with CRP and differential white blood cell count for diagnosis of culture-proven neonatal sepsis. Scand J Infect Dis 2002; 34: 620-2.

46. Adib M, Bakhshiani Z, Navaei F, Fosoul FS, Fouladi S, Kazemzadeh H. Procalcitonin: A reliable marker for the diagnosis of neonatal sepsis. Iran J Basic Med Sci 2012; 15: 777 82 . 